\title{
Formulation, validation and evaluation studies on metaxalone and diclofenac potassium topical gel
}

\author{
Ashutosh Tiwari ${ }^{1}$, Puja Bag ${ }^{2}$, Mrinmoy Sarkar ${ }^{2}\left(\mathbb{D}\right.$, Viney Chawla ${ }^{3(D)}$, and Pooja A. Chawla ${ }^{2, *(D)}$ \\ ${ }^{1}$ Gyani Inder Singh Institute of Professional Studies, Dehradun, Uttarakhand, India \\ ${ }^{2}$ Department of Pharmaceutical Analysis, ISF College of Pharmacy, Moga, Punjab, India \\ ${ }^{3}$ University Institute of Pharmaceutical Sciences, Baba Farid University of Health Sciences, Faridkot, Punjab, India \\ *Correspondence: pvchawla@gmail.com
}

Received: August 26, 2020 Accepted: November 26, 2020

\begin{abstract}
Twenty different batches of gels containing metaxalone and diclofenac potassium were prepared for topical application. These drugs act synergistically in the management of pain and inflammation. Gels were prepared by varying the type of gelling agent (ten batches each of hydroxyl propyl methyl cellulose and carbopol 934). The prepared gels were characterized and evaluated. Batch F7 emerged as the best batch on the basis of favourable $\mathrm{pH}$, high drug content, homogeneity and drug release. HPLC (High-performance liquid chromatography) method validation of gel formulation was also carried out and the developed and validated method was found to be robust and accurate.
\end{abstract}

Keywords: Carbopol, HPMC, Gels, Diclofenac potassium, Metaxalone, Method validation

\section{Introduction}

Pain and inflammation have been haunting the ailing mankind since ages. Whereas inflammation is human body's response to various stimuli including infection, injury and others, pain could have many manifestations like postoperative pain, musculoskeletal pain, arthritic pain, pain due to injury, etc. Non-steroidal anti-inflammatory drugs (NSAIDs) which are orally given are often associated with gastric irritation and ulceration [1]. To overcome these disadvantages and for local action, NSAIDs are often formulated as topical preparations like ointments, creams, gels, etc. Such preparations provide high concentration of required drug at the desired site and avoid systemic side effects. Further, they can be used in nauseated or unconscious patients [2].

Gels are preferred because they are less greasy and can be easily cleared from skin. Gels are characterized as semisolid systems in which the organization of the dispersing medium is controlled by a three-dimensional interlacing network of particles [3]. Metaxalone belongs to the category of muscle relaxants and acts by blocking nerve impulses in the brain. It is preferred in pain caused by sprains, strains and musculoskeletal conditions [4]. Metaxalone is freely soluble in chloroform, soluble in methanol and in $96 \%$ ethanol, but practically insoluble in ether or water. Diclofenac potassium is an arylacetic acid derivative and is known to act by inhibiting the prostaglandin synthesis. Diclofenac binds and chelates both isoforms of cyclooxygenase (COX-1 and -2), thereby blocking the conversion of arachidonic acid to pro-inflammatoryproprostaglandins [5]. It has a pKa of 4.0 and it is freely soluble in methanol. Diclofenac potassium is slightly soluble in water under acidic $\mathrm{pH}$ but solubility increases as the $\mathrm{pH}$ increases to 7.5. Marketed formulations of metaxolone are often associated with a number of side effects like drowsiness, gastrointestinal upset, leucopenia, hemolytic anemia. On the other hand, constipation, flatulence, heartburn, and edema were reported for diclofenac potassium [6].

Pharmaceutical analysis is a branch of practical chemistry which involves a set of procedures to classify, determine, quantify, purify a substance, separate the compounds of a solution or mixture, or determine the structure of chemical substances. The classification of analytical methods includes chemical method (non-aqueous titration, oxidation-reduction, complexometric, gravimetric, etc.), physical methods (polarimetry and refractometry), spectroscopic methods (UV[ultraviolet]-visible spectroscopy, infrared spectroscopy, NMR (nuclear magnetic resonance) spectroscopy, mass spectroscopy, atomic spectroscopy, etc.), and separation method (chromatographic method and electrophoresis). UV-visible spectroscopy is most frequently used techniques in pharmaceutical analysis. Validation of the method is the mechanism used to ensure that the analytical technique employed for a specific test is appropriate for its intended use. Method validation can be used to assess the quality, reliability, and consistency of the analytical results and it is an essential part of good analytical practice. Different parameters of analytical validation are system suitability test, specificity, accuracy, range, 
linearity, precision, etc [7]. The aim of this research was to formulate a gel preparation of metaxolone and diclofenac potassium by and to validate an analytical method for simultaneous estimation of these drugs. By formulating a gel, it is also possible to overcome the side effects associated with oral use of these drugs.

\section{Materials and Methods Materials}

Carbopol 934 was obtained from Titan Biotech Ltd, New Delhi, India. HPMC (Hypromellose) and oleic acid were obtained Central Drug House, New Delhi. Propylene glycol and triethanolamine were supplied by Molychem, Mumbai, India. The drugs, diclofenac potassium and metaxolone were received ex-gratia from Crystal Pharmaceuticals, Ambala, India. All other chemicals used were of analytical grade.

\section{Identification of drugs}

The received samples of drugs were subjected to identification as per the methods given in the Indian Pharmacopoeia, 2018 [8]. Solutions of the drugs were subjected to UV spectroscopy between the range 200-400 nm. Metaxolone exhibited absorption maxima at $273 \mathrm{~nm}$ whereas diclofenac potassium was observed at $280 \mathrm{~nm}$. Further, the drug samples were subjected to IR (infrared) spectroscopy by using $\mathrm{KBr}$ pellet method.

\section{Preformulation studies}

Metaxalone and diclofenac potassium presented as white crystals. They were subjected to solubility studies and melting point determination. Melting point was determined by open capillary method.

\section{Preparation of standard curve}

Solutions of metaxalone in methanol were prepared in the concentration range of $80-800 \mu \mathrm{g} / \mathrm{mL}$ and absorbance was measured at $273 \mathrm{~nm}$. Similarly, diclofenac potassium dilutions in range of 10-100 $\mu \mathrm{g} / \mathrm{mL}$ were prepared in methanol and absorbance recorded at $280 \mathrm{~nm}$. Standard curves were plotted by taking absorbance on Y-axis and concentration of analyte on X-axis.

\section{Preparation of metaxalone and diclofenac potassium topical gel}

A total of twenty batches were prepared, ten each by using carbopol and HPMC. The type and amount of penetration enhancers was varied as per details given in Table 1 and Table 2 . Weighed quantity (125 mg) of carbopol 934 or HPMC was agitated in water with the help of a stirrer for uniform mixing for about 20 minutes followed by addition of penetration enhancers (oleic acid/propylene glycol/Tween 80) to gel base. Accurately weighed amounts of metaxalone and diclofenac potassium were dissolved in methanol. The drug solution was added to polymer at $500 \mathrm{rpm}$ speed with due care to avoid air entrapment. Then $\mathrm{pH}$ of prepared gel was adjusted by adding small amounts of triethanolamine. After that, final volume was adjusted by addition of PEG (polyethylene glycol). Different formulations were prepared as per details recorded in Table 1 for carbopol and Table 2 for hydroxy propyl methyl cellulose (HPMC).

Table 1. Composition of various batches of Carbopol.

\begin{tabular}{|c|c|c|c|c|c|c|c|c|c|c|}
\hline \multirow{2}{*}{ Ingredients } & \multirow{2}{*}{$\begin{array}{c}\text { Control } \\
\text { F1 }\end{array}$} & \multicolumn{3}{|c|}{ Oleic acid } & \multicolumn{3}{|c|}{ Propylene glycol } & \multicolumn{3}{|c|}{ Tween 80} \\
\hline & & F3 & F4 & F5 & F6 & F7 & F8 & F9 & F10 & F11 \\
\hline Carbopol 934 (g) & 0.125 & 0.125 & 0.125 & 0.125 & 0.125 & 0.125 & 0.125 & 0.125 & 0.125 & 0.125 \\
\hline $\operatorname{Drug}^{*}(g)$ & 0.3 & 0.3 & 0.3 & 0.3 & 0.3 & 0.3 & 0.3 & 0.3 & 0.3 & 0.3 \\
\hline Oleic acid (mL) & - & 1.25 & 2.50 & 5.00 & - & - & - & - & - & - \\
\hline Propylene glycol (mL) & - & - & - & - & 1.25 & 2.50 & 5.00 & - & - & - \\
\hline Tween $80(\mathrm{~mL})$ & - & - & - & - & - & - & - & 1.25 & 2.50 & 5.00 \\
\hline Water (mL) & 50 & 50 & 50 & 50 & 50 & 50 & 50 & 50 & 50 & 50 \\
\hline Triethanolamine $(\mathrm{mL})$ & Q.S $S^{* * *}$ & Q.S & Q.S & Q.S & Q.S & Q.S & Q.S & Q.S & Q.S & Q.S \\
\hline PEG $^{* *}$ & Q.S & Q.S & Q.S & Q.S & Q.S & Q.S & Q.S & Q.S & Q.S & Q.S \\
\hline
\end{tabular}

*250 mg of metaxalone and $50 \mathrm{mg}$ of diclofenac potassium was taken as drug

**PEG = Polyethylene glycol

${ }^{* * *}$ Q.S $=$ Quantity sufficient 
Tiwari et al. I Analysis of metaxalone and diclofenac potassium topical gel

Table 2. Composition of various batches of Hypromellose (HPMC)

\begin{tabular}{|c|c|c|c|c|c|c|c|c|c|c|}
\hline \multirow{2}{*}{ Ingredients } & \multirow{2}{*}{$\begin{array}{c}\text { Control } \\
\text { F2 }\end{array}$} & \multicolumn{3}{|c|}{ Oleic acid } & \multicolumn{3}{|c|}{ Propylene glycol } & \multicolumn{3}{|c|}{ Tween 80} \\
\hline & & F12 & F13 & F14 & F15 & F16 & F17 & F18 & F19 & F20 \\
\hline HPMC (g) & 0.125 & 0.125 & 0.125 & 0.125 & 0.125 & 0.125 & 0.125 & 0.125 & 0.125 & 0.125 \\
\hline Drug* (g) & 0.3 & 0.3 & 0.3 & 0.3 & 0.3 & 0.3 & 0.3 & 0.3 & 0.3 & 0.3 \\
\hline Oleic acid (mL) & - & 1.25 & 2.50 & 5.00 & - & - & - & - & - & - \\
\hline Propylene glycol (mL) & - & - & - & - & 1.25 & 2.50 & 5.00 & - & - & - \\
\hline Tween80 (mL) & - & - & - & - & - & - & - & 1.25 & 2.50 & 5.00 \\
\hline Water (mL) & 50 & 50 & 50 & 50 & 50 & 50 & 50 & 50 & 50 & 50 \\
\hline Triethanolamine $(\mathrm{mL})$ & Q.S*** & Q.S & Q.S & Q.S & Q.S & Q.S & Q.S & Q.S & Q.S & Q.S \\
\hline PEG ** & Q.S & Q.S & Q.S & Q.S & Q.S & Q.S & Q.S & Q.S & Q.S & Q.S \\
\hline
\end{tabular}

*250 mg of metaxalone and $50 \mathrm{mg}$ of diclofenac potassium was taken as drug

**PEG $=$ Polyethylene glycol

${ }^{* * *} \mathrm{Q} . \mathrm{S}=$ Quantity sufficient

\section{Evaluation of prepared gels}

Appearance: Colour is important for patient acceptance. The prepared gels were visually evaluated for clarity, colour, and particle's existence.

$p H$ : The $\mathrm{pH}$ of gel was accurately measured by using digital $\mathrm{pH}$ meter as $\mathrm{pH}$ of gel is responsible for skin irritation. The alkaline $\mathrm{pH}$ products should be avoided in sensitive skin. Moreover, skin permeability is also $\mathrm{pH}$ dependent [9].

Viscosity: Viscosity measurement was done by using Brookfield viscometer (Model-LVDV II PLUS PRO). A $10 \mathrm{~g}$ of sample was taken in $50 \mathrm{~mL}$ beaker, dipped the spindle groove and then set the rpm. The readings were taken after a gap of $3 \mathrm{~min}$. This procedure was repeated thrice and average of three determinations was taken. The release and penetration of the drug is known to depend on the viscosity of the formulation [10].

Spreadability: Spreadability of gel was measured by taking about $100 \mathrm{mg}$ of gel and pressed it between 2 slides by $1000 \mathrm{mg}$ of weight then leaving it for $5 \mathrm{~min}$ to compress. Spreadability was calculated by using the following formula:

$S=M * L / T$

where $\mathrm{S}=$ spreadability; $\mathrm{M}$ = weight tied to upper slide; $\mathrm{L}=$ length of glass slide; $\mathrm{T}=$ time taken. Shorter time interval, to cover a distance of $6.5 \mathrm{~cm}$, indicates better spreadability [11].

Homogeneity: Homogeneity of gel was tested through visual inspection for presence of any aggregates. It also can be tested by applying on the skin of a hand.

Grittiness: It is also checked by applying the formulation on the skin of the hand.

Drug content: Accurately weighed $10 \mathrm{mg}$ of formulation was dispersed in phosphate buffer of pH 7.4. Samples were taken from the top, middle and bottom part of formulation. Then the samples were transferred to a volumetric flask and shaken properly using a mechanical shaker for about 1 hour. The contents were filtered and the filtrate was analyzed spectrophotometrically at 250-300 nm for drug content against blank. The concentrations of samples were calculated from the calibration curve [3].

In vitro release studies: This study was performed through cellophane membrane using Franz diffusion cell. The cellophane membrane is previously treated with sodium hydroxide and soaked overnight in phosphate buffer $\mathrm{pH} 7.4$ at room temperature. The treated membrane was placed in diffusion cell between the donor and acceptor compartments. About 2 mg of gel was added to the treated membrane. A magnetic bar was continuously stirring in diffusion medium to avoid diffusion layer effect. Samples were withdrawn at regular intervals and analyzed by UV spectrophotometer at 250-300 nm wavelength [12]. Equal volume of dissolution medium was replaced in the chamber to maintain sufficient volume. 
Method validation: Analytical method was developed and validated as per ICH (International Conference on Harmonization) guidelines. The validation parameters are linearity, accuracy, precision, ruggedness, assay, limit of detection (LOD), and limit of quantification (LOQ).

Specificity: The forced degradation studies were performed to demonstrate selectivity and stability-indicating capability of the proposed method and assessed the analyte response in the presence of its possible impurities. Specificity was checked by following steps $[13,14,15]$.

1. Take a blank sample. i.e. methanol.

2. Take standard metaxalone $(100 \mu \mathrm{g} / \mathrm{mL})$ and diclofenac potassium $(100 \mu \mathrm{g} / \mathrm{mL})$ spectrum.

3. Take gel sample $(100 \mu \mathrm{g} / \mathrm{mL})$ spectrum which contains metaxalone and diclofenac potassium.

Linearity: In an analytical procedure, linearity is the efficiency (within a given range) to achieve test results that are directly proportional to the analyte concentration (amount) in the sample [13]. The linearity of metaxalone and diclofenac potassium dilutions was checked over the range of $80-800 \mu \mathrm{g} / \mathrm{mL}$ and $10-100 \mu \mathrm{g} / \mathrm{mL}$, respectively. $100 \mu \mathrm{g} / \mathrm{mL}$ of solution was taken as $100 \%$ of the dilutions for metaxalone and diclofenac potassium gel. From this, dilutions were prepared according to $50 \%$ (50 $\mu \mathrm{g} / \mathrm{mL}), 60 \%(60 \mu \mathrm{g} / \mathrm{mL}), 70 \%(70 \mu \mathrm{g} / \mathrm{mL}), 80 \%$ (80 $\mathrm{gg} / \mathrm{mL}), 90 \%(90 \mu \mathrm{g} / \mathrm{mL}), 100 \%(100 \mu \mathrm{g} / \mathrm{mL}), 110 \%(110 \mu \mathrm{g} / \mathrm{mL}), 120 \%$ $(120 \mu \mathrm{g} / \mathrm{mL}), 130 \%$ (130 $\mu \mathrm{g} / \mathrm{mL}), 140 \%(140 \mu \mathrm{g} / \mathrm{mL})$, and 150\% (150 $\mu \mathrm{g} / \mathrm{mL})$. The samples were scanned by UV spectrometer using methanol as a blank. It was found that the selected drug present in the gel shows linearity between the ranges of 50 $\mu \mathrm{g} / \mathrm{mL}$ to $150 \mu \mathrm{g} / \mathrm{mL}$. Absorbance of these solutions were measured at $200 \mathrm{~nm}$ to $300 \mathrm{~nm}$. Slope, intercept, and correlation coefficient of standard curves were calculated [14, 15].

Precision: Precision was done by three replicate measurements of three different concentrations. To assess the precision of the method, the intraday ( 3 times) and inter day ( 3 days) measurements of gel sample were completed with computation of \%RSD (relative standard deviation) for replicate samples $(\mathrm{n}=3)$ using concentrations of $50 \%(50 \mu \mathrm{g} / \mathrm{mL}), 100 \%(100$ $\mu \mathrm{g} / \mathrm{mL})$, and $150 \%(150 \mu \mathrm{g} / \mathrm{mL})$ of gel sample containing metaxalone and diclofenac potassium [13, 14, 15]. Both intraday and inter day results were calculated with standard curve concurrently prepared on the day of analysis.

Accuracy: In an analytical procedure, accuracy reveals the closeness of agreement between the values accepted either as a traditional true value or as an adopted reference value, and the value found [13]. The accuracy study was done by adding known amount of pure drug to the previously analyzed solution containing pharmaceutical formulation and the mixture was analyzed by the proposed method and the recoveries were calculated. Standard concentration of sample was taken at $60 \mu \mathrm{g} / \mathrm{mL}$ from which the reference standards of samples were added at the level of $50 \%, 100 \%$, and $150 \%$. The recovery studies were carried out three times, the percent recovery and \%RSD of the recovery of gel sample containing metaxalone and diclofenac potassium, were calculated [14, 15].

Limit of detection (LOD): LOD is the lowest amount of analyte in a sample which can be detected but not necessarily quantitated as an exact value. LOD value was calculated from the calibration curve by using the equation [13] :

$L O D=3.3 * S D /$ slope

where SD is standard deviation of the standard curve.

Limit of quantitation ( $L O Q)$ : LOQ is the lowest amount of analyte in a sample which can be quantitatively determined with suitable precision and accuracy [13]. The quantitation limit is a parameter of quantitative assays for low levels of compounds in sample matrices, and is used particularly for the determination of impurities and/or degradation products. LOQ value can also be calculated from the calibration curve using the equation $[14,15]$ :

$L O Q=10 * S D /$ slope

Ruggedness: In order to check the ruggedness of the method, solutions of same concentration $(100 \mu \mathrm{g} / \mathrm{mL})$ of gel samples containing metaxalone and diclofenac potassium were analyzed by different analysts on the same day. SD and \%RSD were calculated.

Assay: $50 \mathrm{mg}$ of gel was taken and dissolved in $50 \mathrm{~mL}$ methanol. $5 \mathrm{~mL}$ of this solution was diluted to $50 \mathrm{ml}$ with methanol, thus yielding a concentration of $100 \mu \mathrm{g} / \mathrm{ml}$. The amount of drug was determined by measuring the absorbance and later this absorbance was extrapolated to concentration through the use of standard curve [13]. 
Tiwari et al. I Analysis of metaxalone and diclofenac potassium topical gel

\section{Results and Discussion}

The drug samples procured were able to pass the identification tests prescribed in the official monograph. The melting point was found to be $123^{\circ} \mathrm{C}$ for metaxalone and $284^{\circ} \mathrm{C}$ for diclofenac potassium. This was in agreement with standard reported values of $121^{\circ} \mathrm{C}-125^{\circ} \mathrm{C}$ for metaxalone and $283^{\circ} \mathrm{C}-285^{\circ} \mathrm{C}$ for diclofenac potassium, thus confirming that the samples were authentic. Similarly, the observed values of absorption maxima for metaxalone (273 nm) and diclofenac potassium $(280 \mathrm{~nm})$ matched well with literature. The obtained IR spectrum of metaxalone was found to exhibit characteristics absorption bands at $1736.58,1400,1094.4,3282.25$, and $1651 \mathrm{~nm}$ attributed to $\mathrm{C}=\mathrm{O},-\mathrm{CH}, \mathrm{C}-\mathrm{O}, \mathrm{N}-\mathrm{H}$, and C=C, respectively. Absorption bands were observed at 1795.4, 3069.16, 1578.45, 1465.63, and 637.358 nm for functional groups $\mathrm{C}=\mathrm{O}, \mathrm{N}-\mathrm{H}, \mathrm{C}=\mathrm{C}$, and $-\mathrm{CH} 2$, respectively, in case of diclofenac potassium. The compatibility of carbopol and HPMC with metaxalone and diclofenac potassium was also established through FTIR (Fourier-transform infrared spectroscopy) spectra.

The standard calibration curve of metaxalone $\left(Y=0.00511 X-0.0109 ; R^{2}=0.997\right)$ and diclofenac potassium $(Y=$ $\left.0.0088 X-0.0577 ; R^{2}=0.998\right)$ were essentially linear with good correlation coefficient. These equations were used to extrapolate the amount of drug from measured absorbance when required.

A total of twenty batches were prepared: ten each by using carbopol and HPMC. The type and amount of penetration enhancers was varied as per details given in Table 1 and Table 2. The results of evaluation studies on gels revealed that maximum number of formulations were colourless, odourless and exhibited easy spreadability with occlusiveness. The prepared gels were stable with no signs of phase separation (Table 3). The $\mathrm{pH}$ value of various formulations was found to vary between 5.89 to 7.16 (Table 3). This would mean that the prepared gels would be tolerated well. The spreadability of various formulations was found in between $4.1 \mathrm{~cm}$ to $5.6 \mathrm{~cm}$ (Table 3). The viscosity of various formulations was found to vary between 1100 to 98000 centipoises (Table 3).

Majority of the formulations exhibited good homogeneity with no grittiness. The drug content of different formulation was determined by using double beam spectrophotometer (Shimadzu 1800). A drug content of more than $99 \%$ was found in five formulations viz. F3, F7, F9, F14, and F16. The other formulations also recorded excellent drug loading (Table 3). Results of in vitro permeation studies revealed that batches F3, F7 and F9 follow zero order release (Figure 1) thus indicating that the release of drugs from the gels is independent of the concentration and depleting amount of drug in the formulation with time will not be a deterrent to its therapeutic response. The formulation F7 released about $3 / 4^{\text {th }}$ of the loaded drug in 7 hours.

Table 3. Characterization parameters of various formulations

\begin{tabular}{clcccc}
\hline $\begin{array}{c}\text { Formulation } \\
\text { Code }\end{array}$ & Colour & $\begin{array}{c}\text { Spreadability } \\
\text { diameter }(\mathbf{c m})\end{array}$ & pH & Drug loading & $\begin{array}{c}\text { Viscosity } \\
\text { (centipoises) }\end{array}$ \\
\hline F1 & Colourless & 4.2 & 6.18 & $98.29 \pm 0.50$ & 95000 \\
\hline F2 & Colourless & 5.0 & 6.02 & $97.21 \pm 0.90$ & 98000 \\
\hline F3 & White & 4.8 & 6.27 & $99.01 \pm 0.70$ & 8000 \\
\hline F4 & White & 4.6 & 6.78 & $97.69 \pm 0.80$ & 96000 \\
\hline F5 & White & 4.5 & 5.77 & $99.1 \pm 0.42$ & 93000 \\
\hline F6 & Colourless & 5.2 & 5.73 & $97.38 \pm 0.64$ & 88000 \\
\hline F7 & Colourless & 5.6 & 7.14 & $99.24 \pm 1.43$ & 93000 \\
\hline F8 & Colourless & 4.2 & 7.06 & $97.98 \pm 2.29$ & 1740 \\
\hline F9 & Yellowish & 4.0 & 6.52 & $99.41 \pm 0.28$ & 1450 \\
\hline F10 & Yellowish & 4.6 & 5.89 & $98.95 \pm 0.83$ & 1500 \\
\hline F11 & White & 5.1 & 7.11 & $96.85 \pm 0.42$ & 7200 \\
\hline F12 & White & 5.1 & 6.80 & $98.01 \pm 0.50$ & 8400 \\
\hline F13 & White & 4.6 & 7.01 & $97.38 \pm 0.42$ & 83000 \\
\hline F14 & White & 4.2 & 7.13 & $99.33 \pm 0.66$ & 9600 \\
\hline F15 & Colourless & 5.2 & 7.16 & $96.80 \pm 0.55$ & 5100 \\
\hline F16 & Colourless & 5.6 & 6.22 & $99.32 \pm 0.24$ & 3000 \\
\hline F17 & Colourless & 5.4 & 5.88 & $99.01 \pm 0.28$ & 2100 \\
\hline F18 & Colourless & 5.3 & 7.01 & $95.58 \pm 0.33$ & 1820 \\
\hline F19 & Yellowish & 4.8 & 7.12 & $96.11 \pm 0.42$ & 1100 \\
\hline F20 & Colourless & 4.1 & 6.88 & $97.00 \pm 0.80$ & 8000 \\
\hline
\end{tabular}




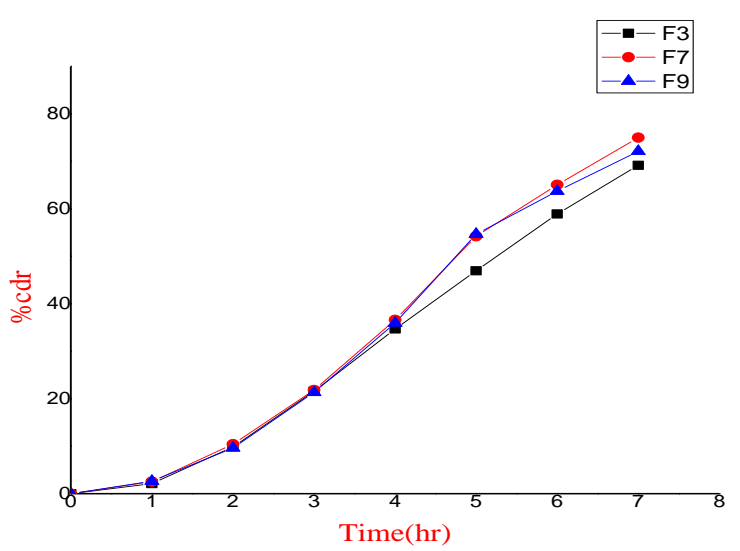

Figure 1. In vitro drug permeation study of carbopol gels (F3, F7 and F9), zero order kinetic model.

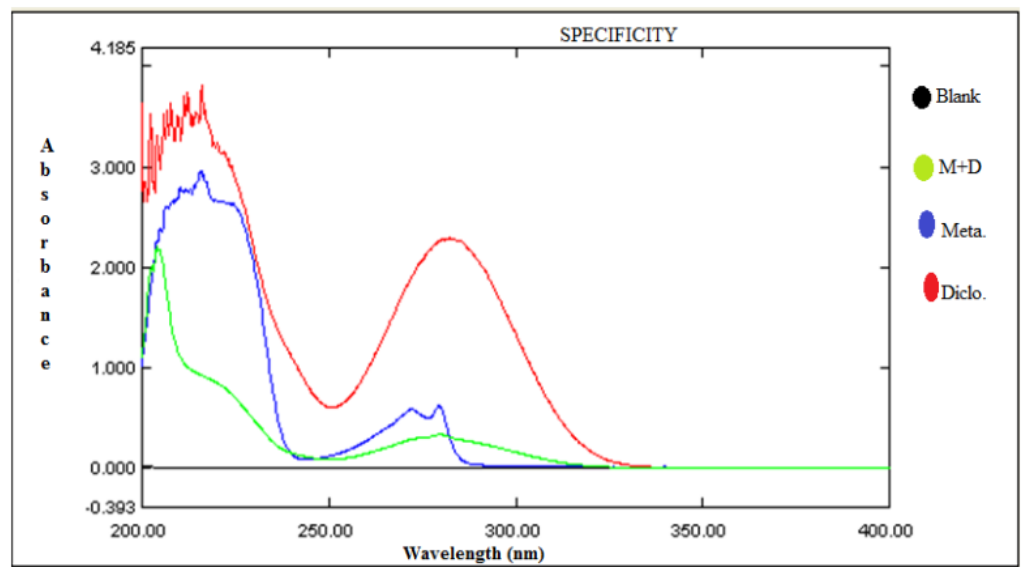

Figure 2. Representative chromatogram on the basics of spectral graph.

\section{Results of validation}

Specificity: Specificity is the ability to assess unequivocally the analyte in the presence of components which may be expected to be present. A representative chromatogram (Figure 2) indicates that commonly used gel additives did not interfere with the method and no significant changes in retention times of the drugs were observed in the presence or absence of additives.

Linearity: The analysis of gel formulation containing metaxalone and diclofenac potassium revealed strictly linear relationship with absorbance in the studied concentration range. The slope, intercept and correlation coefficient values were $0.005,0.073$ and 0.994 (Figure 3).

Precision: Intra-day and inter-day precision experiments were performed. The \%RSD values for precision were less than 2 , there by indicating that the method was sufficiently precise (Table 4).

Accuracy: The values of recovery were in between $98-100 \%$ and percent relative standard deviation was less than 2 indicating that the method is accurate.

Limit of detection (LOD) and Limit of quantitation (LOQ): The value of LOD and LOQ was found to be $2.820 \mu \mathrm{M}$ and 8.546 $\mu \mathrm{M}$ (Table 4).

Ruggedness: The ruggedness value found in respect of SD and \%RSD was 0.0063 and 1.01, respectively (Table 4).

Assay: The assay value was found to be $99.52 \%$ and \%RSD was found to be 0.737 (Table 4). 
Tiwari et al. I Analysis of metaxalone and diclofenac potassium topical gel

Table 4. Validation parameters of the developed HPLC (High-performance liquid chromatography) method.

\begin{tabular}{cc}
\hline Name of parameter & Reported value \\
\hline Limit of detection (LOD) & $2.820 \mu \mathrm{M}$ \\
\hline Limit of quantitation (LOQ) & $8.546 \mu \mathrm{M}$ \\
\hline Ruggedness & ${\text { SD* }=0.0063 ; \% \mathrm{RS}^{*}=1.01}^{*}$ Assay (\%) \\
\hline Intraday precision & $99.52 \pm 0.737$ \\
\hline Interday precision & $0.429 \pm 0.0026$ \\
\hline
\end{tabular}

* SD = standard deviation; RSD = relative standard deviation

\section{Conclusions}

Metaxalone and diclofenac potassium gels were successfully formulated using carbopol and HPMC. It was observed that Metaxalone and diclofenac potassium gel containing carbopol 934 and $2.5 \mathrm{~mL}$ of propylene glycol show better spreadability, viscosity, and consistency as compared to other formulations. The batch F7 (Carbopol 934 gel with $2.5 \mathrm{~mL}$ of Propylene glycol) showed good $\mathrm{pH}$, drug content, homogeneity and in vitro release. Hence, F7 formulation has wider prospects to be used as a topical drug delivery system. The release of gel containing metaxalone and diclofenac potassium was good fit to the zero-order kinetic model. The release rate is independent of the concentration of the drug. Further, the optimized and validated UV spectroscopic method is simple, sensitive, precise, accurate, and reproducible. It also meets the required acceptance criteria given in $\mathrm{ICH}$ guidelines. Hence, it can be used in routine analysis for the simultaneous estimation of gel containing metaxalone and diclofenac potassium.

\section{Acknowledgement}

The authors are thankful to the management of Gyani Inder Singh Institute of Professional Studies, Dehradun, India for providing the research facilities.

\section{Conflict of interest}

The authors declare no conflict of interest.

\section{CRediT author statement}

AT: Experimentation, Investigation, Visualization, Results compilation; PB: Writing-Original draft preparation, Editing; MS: Validation, Results compilation; VC: Critical review, revision, project administration; PAC: Data curation and analysis, Supervision, Reviewing, Editing

\section{ORCID}

Ashutosh Tiwari: 0000-0002-5672-0344

Puja Bag: 0000-0002-9329-8701

Mrinmoy Sarkar: 0000-0001-9013-144X

Viney Chawla: 0000-0001-8522-7148

Pooja A Chawla: 0000-0001-7844-9172

\section{References}

[1] Russell R. Non-steroidal anti-inflammatory drugs and gastrointestinal damage-problems and solutions. Postgrad Med J 2001;77(904):82-88.

[2] Stanos S. Topical Analgesics. Phys Med Rehabil Clin N Am 2020;31(2):233-244.

[3] Jayaraj K, Gopi S, Rajeswari A, Christy EJS, Pius A. Microscopic studies on chitin and chitosan-based interpenetrating polymer networks, gels, blends, composites, and nanocomposites. In: Gopi S, Thomas S, Pius A, editors. Handbook of chitin and chitosan, $1^{\text {st }}$ ed. Elsevier; 2020, 95-138.

[4] Marcum ZA, Duncan NA, Makris UE. Pharmacotherapies in geriatric chronic pain management. Clin Geriatr Med 2016;32(4):705-724. 
[5] Osafo N, Agyare C, Obiri DD, Antwi AO. Mechanism of action of anti-inflammatory drugs. In: Al-kaf AGA, editor. Non steroidal anti-inflammatory drugs, $1^{\text {st }}$ ed. Intech Open; 2017, 5-15

[6] Gan TJ. Diclofenac: an update on its mechanism of action and safety profile. Curr Med Res Opin 2010;26(7):17151731.

[7] Schepers U, El Deeb S, Ermer J, Wätzig H. Comparison of the recovery spread in analytical development and routine quality control-Based on the ICH quality guideline Q2B. J Pharmaceut Biomed Anal 2007;43(2):708-710.

[8] Indian Pharmacopoeia. Published by Indian Pharmacopoeia Commission. 2018, Vol. II, 1806-1807.

[9] Michaels AS, Chandrasekaran SK, Shaw JE. Drug permeation through human skin: theory and in vitro experimental measurement. AIChE J 1975;21(5):985-996.

[10] Welin-Berger K, Neelissen JA, Bergenstahl B. The effect of rheological behaviour of a topical anaesthetic formulation on the release and permeation rates of the active compound. Eur J Pharm Sci 2001;13(3):309-318.

[11] Garg A, Aggarwal D, Garg S, Singla AK. Spreading of semisolid formulations: an update. Pharm Tech 2002;26(9):84-105.

[12] Yamaguchi Y, Sato H, Sugibayashi K, Morimoto Y. Drug release test to assess quality of topical formulations in Japanese market. Drug Dev Ind Pharm 1996;22(7):569-577.

[13] Guideline IHT. October. Text on validation of analytical procedures. In International Conference on Harmonization, Geneva. 1994; 1-5.

[14] Shabir GA. Step-by-step analytical methods validation and protocol in the quality system compliance industry. J Valid Technol 2005;10:314-325.

[15] International Conference on Harmonization (ICH). Guidance for industry: Q2B validation of analytical procedures: methodology. In: International Conference on Harmonisation. Brussels, Belgium; 1996 